\title{
Antibiotic Resistance of Sorbitol Non-Fermenting Shiga Toxin Producing Escherichia coli Isolated from Buffaloes
}

\author{
Md Shahriar Mannan ${ }^{1}$, Abdullah Al Momen Sabuj ${ }^{2}$, Modhan Kumar Ray ${ }^{1}$, Farzana Rabbi ${ }^{3}$, Zamila \\ Bueaza Bupasha ${ }^{4}$ and Md Samun Sarker ${ }^{4,5^{*}}$
}

${ }^{1}$ Veterinary Surgeon, Department of Livestock Services, Bangladesh; ${ }^{2}$ Department of Microbiology and Hygiene, Faculty of Veterinary Science, Bangladesh Agricultural University, Mymensing-2202, Bangladesh; ${ }^{3}$ Department of Physiology, Biochemistry and Pharmacology, Faculty of Veterinary Medicine, Chattogram Veterinary and Animal Sciences University, Chattogram-4225, Bangladesh; ${ }^{4}$ Department of Microbiology and Veterinary Public Health, Faculty of Veterinary Medicine, Chattogram Veterinary and Animal Sciences University, Chattogram-4225, Bangladesh; ${ }^{5}$ Antimicrobial Resistance Action Center (ARAC), Bangladesh Livestock Research Institute (BLRI), Dhaka, Bangladesh

*Corresponding author: samuncvasu@gmail.com

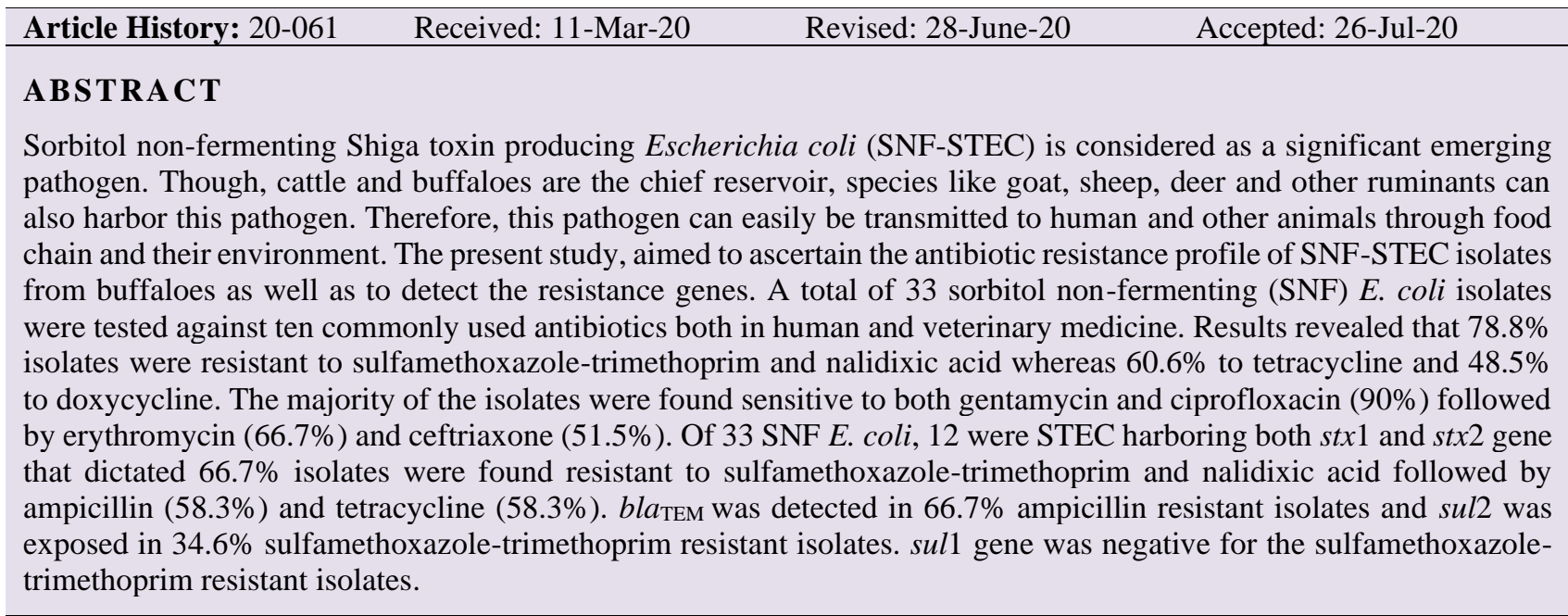

Key words: Antibiotic resistance, Buffalo, Escherichia coli and SNF-STEC.

\section{INTRODUCTION}

Escherichia coli, enteric pathogens, shares multi host system including human, livestock and primates (Mercat et al. 2014). Shiga toxin producing E. coli (STEC) is considered as foremost food borne pathogens having public health significance and causes diarrhea (Asakura et al. 2014). SNF-STEC is unable to ferment sorbitol which causes acute and serious diseases like hemolytic uremic syndrome (HUS), hemorrhagic colitis and thrombotic thrombocytopenia in humans (Sun et al. 2016; Kwan et al. 2019). Domestic animal particularly bovine and ovine is mostly affected through this pathogen worldwide (Oliveira et al. 2007). Cattle, major reservoir for STEC (Bono et al. 2012) and other species like goat, sheep or deer also act as a reservoir (Bhat et al. 2008; Sanchez et al. 2009). Human get infection of STEC through contaminated food (Kwan et al. 2019) but in the farm land it can be transmitted through contaminated feces, water, insects, wild birds and even throughout animal (Vogeleer et al. 2004). However, buffalo, another ruminant, can also be acted as reservoir for pathogenic STEC (Beraldo et al. 2014).

The total buffalo population in Bangladesh is about 1.47 million and most of them reared in saline coastal area, mainly used for draught animal as well as for meat and milk production (Hamid et al. 2016). Treatment of different bacterial diseases by antimicrobials in a suboptimal or incomplete dose may develop antimicrobial resistance in animals. Recently in Bangladesh, a report has been published on STEC in buffalo calves with a prevalence of $11.01 \%$ (Gupta et al. 2018) and another study in India with a prevalence of $35.01 \%$ (Srivani et al. 2017). Limited number

Cite This Article as: Mannan MS, Sabuj AAM, Ray MK, Rabbi F, Bupasha ZB and Sarker MS, 2021. Antibiotic resistance of sorbitol non-fermenting Shiga toxin producing Escherichia coli isolated from buffaloes. International Journal of Veterinary Science 10(1): 51-54. https://doi.org/10.47278/journal.ijvs/2020.024 
of works has been done so far in Bangladesh on STEC in different farm animals especially in cattle (Islam et al. 2014) and buffalo (Gupta et al. 2018). However, antibiotic resistant STEC might be source of resistance genes that could be transmitted horizontally to human leads to treatment failure. Therefore, the current study was conducted to detect the antibiotic resistance along with the resistant genes in SNF-STEC isolates of buffalo.

\section{MATERIALS AND METHODS}

\section{Source of Isolates}

A total of 33 SNF E. coli isolates, of which 12 were STEC used from a preceding study (Mannan, 2015). In brief, total 308 fecal swab samples from recto-anal junction of apparently healthy buffalos were collected aseptically from coastal area in Chattogram Division, Bangladesh during the period January to June 2014. After bacteriological and biochemical confirmation, 33 isolates were detected as SNF $E$. coli that we have been used in our present study.

\section{Antibiotic Susceptibility Testing}

Mueller-Hinton agar (Oxoid, UK) plate was used to perform the antibiotic susceptibility of SNF E. coli isolates based on the guidelines and recommendations of CLSI (2012). The following ten commonly used antibiotics both in human and veterinary practices were tested namely ampicillin $(10 \mu \mathrm{g})$, ceftriaxone $(30 \mu \mathrm{g})$, chloramphenicol $(30 \mu \mathrm{g})$, tetracycline $(30 \mu \mathrm{g})$, sulfamethoxazoletrimethoprim $(25 \mu \mathrm{g})$, nalidixic acid $(30 \mu \mathrm{g})$, erythromycin (15 $\mu \mathrm{g})$, doxycycline $(5 \mu \mathrm{g})$, gentamicin $(10 \mu \mathrm{g})$ and ciprofloxacin $(5 \mu \mathrm{g})$ (Oxoid, UK). The antibiotic susceptibility results were interpreted by CLSI (2012).

\section{Chromosomal DNA Extraction}

Boiling method was used to extract the total DNA (Sánchez et al. 2009). Briefly, freshly cultured two to three colonies were taken into $1.5 \mathrm{ml}$ sterile Eppendorf tube confined $200 \mu \mathrm{l}$ of nuclease free water and vortexed thoroughly. At $99^{\circ} \mathrm{C}$, the tube was heated for 10 minutes and centrifuged at $15000 \mathrm{rpm}$ for 2 minutes. The collected supernatant was used as a DNA template and for further use stored at $-20^{\circ} \mathrm{C}$.

\section{Amplification of Antibiotic Resistant Genes}

To amplify the antibiotic resistant genes, PCR was performed in a Thermocycler (Applied Biosystems, 2720 Thermal cycler, USA), using $25 \mu$ l final volume containing of $12.5 \mu \mathrm{l}$ Go Taq master mixes (Promega, USA), $0.5 \mu \mathrm{l}$ of each primer, $2 \mu \mathrm{l}$ DNA template and deionized water, $9.5 \mu \mathrm{l}$. Conditions of PCR were described in the earlier published paper (Belaaouaj et al. 1994; Sunde, 2005; Change et al. 2007). The primers used in this study are enlisted in Table 1. $1.5 \%$ agarose gels stained with ethidium bromide $(10 \mathrm{mg} / \mathrm{ml})$ (Thermo Scientific, USA) was used to electrophorese the PCR products and finally inspected under an ultraviolet transilluminator (BDA digital, Germany).

\section{RESULTS}

All the 33 SNF E. coli isolates were tested against 10 different antibiotic agents for susceptibility testing that represented in Fig. 1. Results revealed that $78.8 \%$ isolates were resistant to sulfamethoxazole-trimethoprim and nalidixic acid. Tetracycline and doxycycline were resistant to $60.6 \%$ and $48.5 \%$ isolates, respectively. On the contrary, $90.9 \%$ isolates were found sensitive to gentamycin and ciprofloxacin followed by erythromycin (66.7\%), doxycycline $(51.5 \%)$ and ceftriaxone $(51.5 \%)$.

The susceptibility of stx 1 and stx 2 genotypic isolates are exhibited in Table 2. Among 12 STEC (carrying both st $x 1$ and st 2 gene) isolates, highest resistance (66.7\%) was observed to sulfamethoxazole-trimethoprim and nalidixic acid. Of the tested st $x 1$ genotypic isolates, $75 \%$ were found resistance against sulfamethoxazole-trimethoprim whereas ampicillin $(75 \%)$ and nalidixic acid $(75 \%)$ was the most prevalent resistance in $s t x 2$ isolates.

Three of the targeting antibiotics resistant geneshave amplified, that is bla $a_{\mathrm{TEM}}$ for ampicillin resistant and sul 1 and sul2 for sulfamathoxazole-trimethoprim resistant. Out of 15 ampicillin resistant isolates, $10(66.7 \%)$ isolates exposed bla $a_{\text {TEM }}$ genes. In case of 26 sulfamathoxazole-trimethoprim resistant isolates, sul2 was the prevalent $(34.6 \%, \mathrm{n}=9 / 26)$ gene whereas none of the isolates revealed sul1 gene.

Table 1: Primers used to identify antibiotic resistant genes, blaTEM, sul 1 and sul2

\begin{tabular}{lcc}
$\begin{array}{l}\text { Target } \\
\text { genes }\end{array}$ & Primer sequence $\left(5^{\prime}-3^{\prime}\right)$ & $\begin{array}{l}\text { Amplic References } \\
\text { on size }\end{array}$ \\
\hline bla $_{\text {TEM }}$ & F: TACGATACGGGAGGGCTTAC & 716-bp Belaaouaj et \\
& R: TTCCTGTTTTGCTCACCCA & al. (1994) \\
sul 1 & F: CGGCGTGGGCTACCTGAACG & 433-bp Sunde (2005) \\
& R: GCCGATCGCGTGAAGTCCG & 435-bp Change et al. \\
sul 2 & F: GAAGCGCAGCCGCAATCAT & 435- \\
& R: TGTGCGGATGAAGTCAGCTC & $(2007)$ \\
\hline
\end{tabular}

Table 2: Frequency of antibiotic resistance in relation to Shiga toxin producing genes

\begin{tabular}{llcl}
\hline Antibiotic agents & \multicolumn{1}{c}{$s t x 1$} & $s t x 2$ & $s t x 1 / s t x 2$ \\
$\mathrm{n}=8(\%)$ & $\mathrm{n}=4(\%)$ & $\mathrm{n}=12(\%)$ \\
\hline AMP & $4(50.0)$ & $3(75)$ & $7(58.3)$ \\
CRO & $3(37.5)$ & $1(25)$ & $4(33.3)$ \\
C & $3(37.5)$ & $2(50)$ & $5(41.7)$ \\
TE & $5(62.5)$ & $2(50)$ & $7(58.3)$ \\
SXT & $6(75.0)$ & $2(50)$ & $8(66.7)$ \\
NA & $5(62.5)$ & $3(75)$ & $8(66.7)$ \\
E & $3(37.5)$ & $1(25)$ & $4(33.3)$ \\
DOX & $3(37.5)$ & $2(50)$ & $541.7)$ \\
CN & $0(0)$ & $0(0)$ & $0(0)$ \\
CIP & $1(12.5)$ & $0(0)$ & $1(8.3)$ \\
\hline
\end{tabular}

AMP; ampicillin, CRO; ceftriaxone, C; chloramphenicol, TE; tetracycline, SXT; sulfamethoxazole-trimethoprim, NA; nalidixic acid, E; erythromycin, DOX; doxycycline, CN; gentamicin, CIP; ciprofloxacin.

\section{DISCUSSION}

Based on vigorous literature searches, this is the first report of antibiotic resistant SNF $E$. coli isolates in buffaloes in Bangladesh. However, at the same study area, antibiotic resistant of SNF E. coli was determined in cattle (Islam et al. 2014). In this study, high resistance rate was perceived to sulfamethoxazole-trimethoprim, nalidixic acid and tetracycline, an agreement with the previous reports on buffalo in Egypt and Iran (Shahrani et al. 2014; Abdulgayeid et al. 2015). Higher resistance to these antibiotics was also found in other species in several preceding studies (Galland et al. 2001; Islam et al. 2014; Dorgham et al. 2019; El Jalil et al. 2020). 
Int J Vet Sci, 2021, 10(1): 51-54.

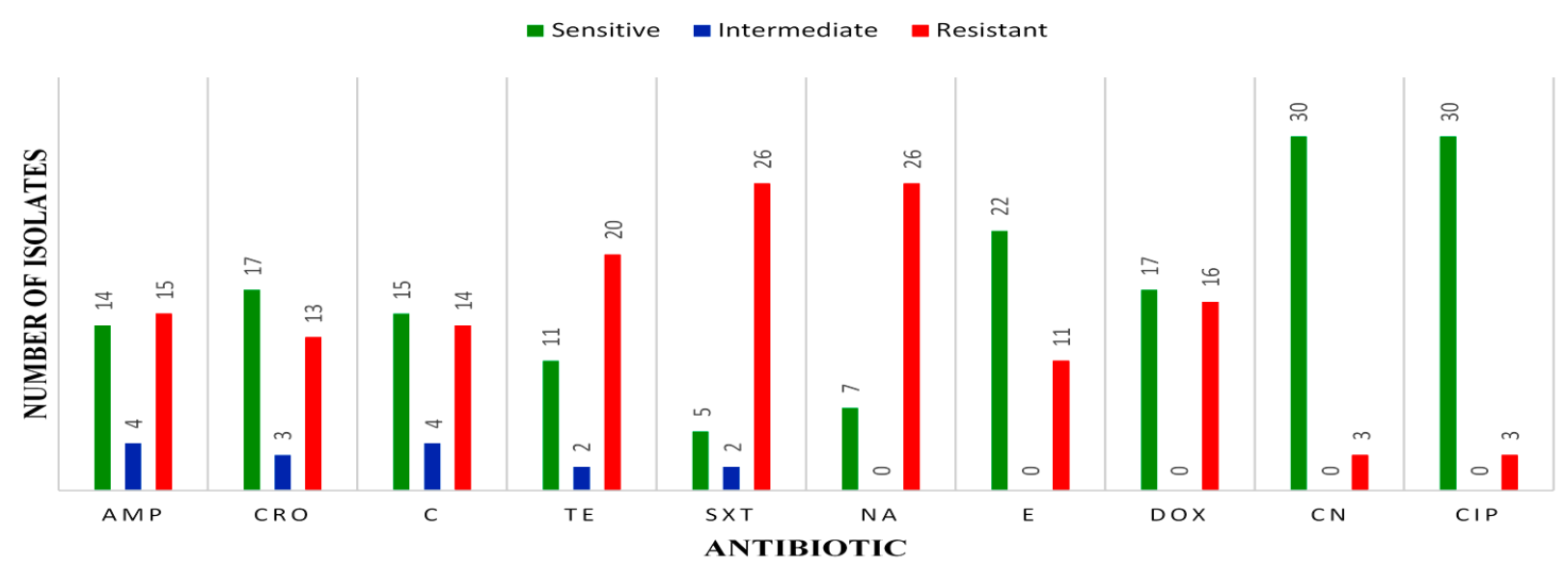

Fig. 1: Antibiotic susceptibility results of SNF E. coli isolates (N=33).

Resistances of these drugs are not surprising as they are very commonly used to treat bacterial diseases in buffalo. Tetracycline is commonly used in food animal production as growth promoter in animal feed and antibiotic therapy. However, isolates were found sensitive to gentamicin, ciprofloxacin, erythromycin and ceftriaxone, agreement with the resistant pattern of SNF-STEC from cattle in Bangladesh (Islam et al. 2014; Mehmood et al. 2020).

In current study, STEC isolates harboring stx 1 and stx 2 both genes were found resistance $(66.7 \%)$ to sulfamethoxazole-trimethoprim and nalidixic acid followed by tetracycline (58.3\%) and ampicillin (58.3\%) which is parallel with the findings of Gupta et al. (2018), informed that STEC genes were found resistant to sulfamethoxazole-trimethoprim $(73 \%)$ and ampicillin (55\%). On the contrary, Srivani et al. (2017) noted lower resistance against sulfamethoxazole (28.30\%) and amoxicillin $(20.75 \%)$. This variation could be attributed to the variation of sample size, geographical location, choice of antibiotics etc. Fascinatingly, isolates also found sensitive to gentamicin, ciprofloxacin, ceftriaxone, erythromycin, and chloramphenicol. This finding was in the line of Gupta et al. (2018), who claimed that chloramphenicol, ciprofloxacin and gentamycin were sensitive to STEC isolates of buffalo calves. These antibiotics could be a good alternative for STEC infection in human and animals, though further clinical trials are suggested.

Among three antibiotic resistance genes, bla $a_{\text {TEM }}$ was the most prevalent one, $66.7 \%$. However, bla in lesser extent in Iran (Dehdashti et al. 2019). 34.6\% resistant isolates in this study exposed sul2 that comparatively higher than another study, discovered $11 \%$ (Dehdashti et al. 2019). E. coli isolates from buffalo were positive for sul2 genes, $31 \%$ in Pakistan closer to our current findings (Idrees et al. 2011). None of the sulfamethoxazole-trimethoprim resistant isolates exposed sul1 gene. Resembling to our study, antibiotic resistance and these genes have been determined in $E$. coli isolates from sheep, goat, cattle, buffaloes, broiler and even in the wildlife in Bangladesh (Zinnah et al. 2008; Gupta et al. 2017; Sarket et al. 2019a; Sarker et al. 2019b). These resistance genes can easily transmit to human and animals through food chain, drinking water or environment which might pose serious health risk. So, careful selection of antimicrobial drug and maintaining proper dose and course might reduce the emergence of such SN-F-STEC organisms.

\section{Conclusions}

The study revealed the high frequency of antibiotic resistant with the existence of resistant genes in SNF STEC isolates in healthy buffaloes for the first time in Bangladesh. In this study, high resistance was found to sulfamethoxazole-trimethoprim $(78.8 \%)$, nalidixic acid (78.8\%) and tetracycline (60.6\%). Of 33 SNF E. coli, 12 were STEC harboring both stx 1 and st $x 2$ gene. Of the 3 tested genes, bla $a_{\mathrm{TEM}}$ was detected in $66.7 \%$ and $s u l 2$ was exposed in $34.6 \%$ resistant isolates. None of the sulfamethoxazole-trimethoprim resistant isolates was positive for sul1 gene.

\section{Author's contribution}

MSM and FR designed the research. MSM and ZBB performed the laboratory work. AAMS and MSS wrote the manuscript. MKR and MSS critically revised the manuscript.

\section{REFERENCES}

Abdulgayeid M, Shahin H, Foad S and Ibrahim MS, 2015. Molecular characterization of Escherichia coli isolated from buffalo calves in El-Behera Governorate. Alexandria Journal of Veterinary $\quad$ Sciences 47: https://doi.org/10.5455/ajvs.202843.

Asakura H, Masuda K, Yamamoto S and Igimi S, 2014. Molecular approach for tracing dissemination routes of Shiga toxin-producing Escherichia coli 0157 in bovine offal at slaughter. Biomed Research International 2014: Article \# 739139. https://doi.org/10.1155/2014/739139.

Belaaouaj A, Lapoumeroulie C, Caniça MM, Vedel G, Névot P, Krishnamoorthy R and Paul G, 1994. Nucleotide sequences of the genes coding for the TEM-like $\beta$-lactamases IRT-1 and IRT-2 (formerly called TRI-1 and TRI-2). FEMS Microbiology Letters 120: 75-80. https://doi.org/10.1111/j.1574-6968.1994.tb07010.x.

Beraldo LG, Borges CA, Maluta RP, Cardozo MV, Rigobelo EC and de Ávila FA, 2014. Detection of Shiga toxigenic (STEC) and enteropathogenic (EPEC) Escherichia coli in dairy buffalo. Veterinary Microbiology 170: 162-166. https://doi.org/10.1016/j.vetmic.2014.01.023. 
Bhat MA, Nishikawa Y and Wani SA, 2008. Prevalence and virulence gene profiles of Shiga toxin-producing Escherichia coli and enteropathogenic Escherichia coli from diarrhoeic and healthy lambs in India. Small Ruminant Research 75: 65-70. https://doi.org/10.1016/j.small rumres. 2007.08.006.

Bono JL, Smith TP, Keen JE, Harhay GP, McDaneld TG, Mandrell RE, Jung WK, Besser TE, Peter Gerner-Smidt P, Bielaszewska M and Karch H, 2012. Phylogeny of Shiga toxin-producing Escherichia coli $\mathrm{O} 157$ isolated from cattle and clinically ill humans. Molecular Biology and Evolution 29: 2047-2062. https://doi.org/10.1093/molbev/mss072

Chang LL, Lin HH, Chang CY and Lu PL, 2007. Increased incidence of class 1 integrons in trimethoprim/ sulfamethoxazole-resistant clinical isolates of Stenotrophomonas maltophilia. Journal of Antimicrobial Chemotherapy 59: 1038-1039. https://doi.org/10.1093/ jac/dkm034

CLSI, 2012. Performance Standards for Antimicrobial Disk Susceptibility Tests; Approved Standard. 11th ed. Document M02-A11. Clinical and Laboratory Standards Institute, Wayne, PA.

Dehdashti S, Ghanbarpour R and Hajikolaei MRH, 2019. Molecular detection of Shiga toxin-producing and antibiotic-resistant Escherichia coli isolates from buffaloes in southwest of Iran. Tropical Animal Health Production 51: 1725-1736. https://doi.org/10.1007/s11250-019-01869-3.

Dorgham SM, RH Hedia, AA Arafa, EA Khairy and MM Kandil, 2019. Antibiotic resistance pattern and biofilm genes of different Salmonella serotypes isolated from chicken samples. International Journal of Veterinary Science 8: 324- 328.

El Jalil MH, Khamar M, Maaninou S, Dahha M, Zinedine A and Ameur N, 2020. Antibiotic resistance of Escherichia coli strains isolated from broiler meat in Morocco. International Journal of Veterinary Science 9: 305-308. https://doi.org/10.37422/IJVS/20.015

Galland JC, Hyatt DR, Crupper SS and Acheson DW, 2001. Prevalence, antibiotic susceptibility, and diversity of Escherichia coli $\mathrm{O} 157$ : $\mathrm{H} 7$ isolates from a longitudinal study of beef cattle feedlots. Applied and Environmental Microbiology 67: 1619-1627. https://doi.org/10.1128/ AEM.67.4.1619-1627.2001

Gupta MD, Islam M, Sen A, Sarker MS and Das A, 2017. Prevalence and antibiotic susceptibility pattern of Escherichia coli in cattle on Bathan and intensive rearing system. Microbes and Health 6: 1-4. https://doi.org/10.3329/ mh.v6i1.34062.

Gupta MD, Sen A and Das A, 2018. Occurrence of Escherichia coli carrying Shiga toxin-producing genes in buffaloes on smallholdings in Bangladesh. Veterinary World 11: 14541458. https://doi.org/10.14202/vetworld.2018.1454-1458.

Hamid MA, Ahmed S, Rahman MA, and Hossain KM, 2016. Status of buffalo production in Bangladesh compared to SAARC countries. Asian Journal of Animal Sciences 10: 313-329. https://doi.org/10.3923/ajas.2016.313.329.

Idrees M, Shah MA, Michael S, Qamar R and Bokhari H, 2011. Antimicrobial resistant Escherichia coli strains isolated from food animals in Pakistan. Pakistan Journal of Zoology 43: 303-310.

Islam MZ, Ahad A and Biswas PK, 2014. Antimicrobial resistance profile of sorbitol non-fermenting Shiga toxin producing Escherichia coli isolated from smallholdings cattle. Journal of Infection and Molecular Biology 1: 58-63.

Kwan SY, Chang WS, Loo YY, Nordin Y, Tan CW, Kuan CH, New CY, Lee E, Nor-Khaizura MAR and Son R, 2019. Prevalence and antibiotic profile of Shiga-toxin producing Escherichia coli and Escherichia coli O157: $\mathrm{H} 7$ in beef and buffalo. Food Research 3: 28-39. https://doi.org/10.26656/ fr.2017.3(1).218.
Mannan MS, 2015. An investigation on sorbitol non fermenting Shiga toxin producing $E$. coli in healthy buffaloes in Chittagong, Bangladesh. MS thesis, pp: 29-30.

Mehmood K, Bilal RM and Zhang H, 2020. Study on the genotypic and phenotypic resistance of tetracycline antibiotic in Escherichia coli strains isolated from free ranging chickens of Anhui Province, China. Agrobiological Records 2: 63-68. https://doi.org/10.47278/ journal.abr/2020.014

Mercat M, Clermont O, Massot M, Ruppe E, de GarineWichatitsky M, Miguel E, Fox HV, Cornelis D, Andremont A, Denamur E and Caron A, 2016. Escherichia coli population structure and antibiotic resistance at a buffalo/cattle interface in southern Africa. Applied and Environmental Microbiology 82: 1459-1467. https://doi.org/ 10.1128/AEM.03771-15.

Oliveira MG, Brito JRF, Carvalho RR, Guth BEC, Gomes TAT, Vieira MAM, Kato MAMF, Ramos II, Vaz TMI and Kinue Irino, 2007. Water buffaloes (Bubalus bubalis) identified as an important reservoir of Shiga toxin-producing Escherichia coli in Brazil. Applied and Environmental Microbiology 73: 5945-5948. https://doi.org/10.1128/AEM.00929-07.

Sánchez S, García-Sánchez A, Martínez R, Blanco J, Blanco JE, Blanco M, Dahbi G, Mora A, de Mendoza JH, Alonso JM and Rey J, 2009. Detection and characterization of Shiga toxin-producing Escherichia coli other than Escherichia coli O157: H7 in wild ruminants. The Veterinary Journal 180: 384-388. https://doi.org/10.1016/j.tvj1.2008.01.011.

Sarker MS, Ahad A, Ghosh SK, Mannan MS, Sen A, Islam S, Mand B and Bupasha ZB, 2019a. Antibiotic-resistant Escherichia coli in deer and nearby water sources at Safari parks in Bangladesh. Veterinary World 12: 1578-1583. https://doi.org/10.14202/vetworld.2019.1578-1583.

Sarker MS, Mannan MS, Ali MY, Bayzid M, Ahad A and Bupasha ZB, 2019b. Antibiotic resistance of Escherichia coli isolated from broilers sold at live bird markets in Chattogram, Bangladesh. Journal of Advanced Veterinary and Animal Research, 6: 272-277. https://doi.org/ 10.5455/javar.2019.f344.

Shahrani M, Dehkordi FS and Momtaz H, 2014. Characterization of Escherichia coli virulence genes, pathotypes and antibiotic resistance properties in diarrheic calves in Iran. Biological Research 47: 28.

Srivani M, Reddy YN, Subramanyam KV, Reddy MR and Rao TS, 2017. Prevalence and antimicrobial resistance pattern of Shiga toxigenic Escherichia coli in diarrheic buffalo calves. Veterinary World 10: 774-778. https://doi.org/ 10.14202/vetworld.2017.774-778.

Sun X, Lei C, Guo L and Zhou Y, 2016. Separable detecting of Escherichia coli $\mathrm{O} 157 \mathrm{H}$ : $\mathrm{H} 7$ by a giant magneto-resistancebased bio-sensing system. Sensors and Actuators B: Chemical 234: 485-492. https://doi.org/10.1016/ j.snb. 2016.04.183.

Sunde M, 2005. Prevalence and characterization of class 1 and class 2 integrons in Escherichia coli isolated from meat and meat products of Norwegian origin. Journal of Antimicrobial Chemotherapy 56: 1019-1024. https://doi.org/10.1093/ jac/dki377.

Vogeleer P, Tremblay YD, Mafu AA, Jacques M and Harel J, 2014. Life on the outside: role of biofilms in environmental persistence of Shiga-toxin producing Escherichia coli. Frontiers in Microbiology 5: 317.

Zinnah MA, Haque MH, Islam M, Hossain MT, Bari MR, Babu SAM, Rahman MT and Islam MA, 2008. Drug sensitivity pattern of $E$. coli isolated from samples of different biological and environmental sources. Bangladesh Journal of Veterinary Medicine 6: 13-18. https://doi.org/10.3329/ bjvm.v6i1.1332. 